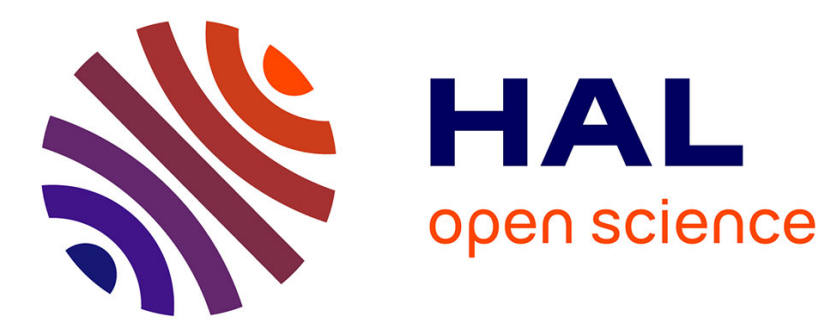

\title{
PdPt catalyst synthesized by gas aggregation source and magnetron sputtering for fuel cell electrodes
}

\author{
A Caillard, S Cuynet, T Lecas, Pascal Andreazza, Maxime Mikikian, A-L \\ Thomann, Pascal Brault
}

\section{> To cite this version:}

A Caillard, S Cuynet, T Lecas, Pascal Andreazza, Maxime Mikikian, et al.. PdPt catalyst synthesized by gas aggregation source and magnetron sputtering for fuel cell electrodes. Journal of Physics D: Applied Physics, 2015, 48, pp.475302. 10.1088/0022-3727/48/47/475302 . hal-01220392

\section{HAL Id: hal-01220392 \\ https://hal.science/hal-01220392}

Submitted on 26 Oct 2015

HAL is a multi-disciplinary open access archive for the deposit and dissemination of scientific research documents, whether they are published or not. The documents may come from teaching and research institutions in France or abroad, or from public or private research centers.
L'archive ouverte pluridisciplinaire HAL, est destinée au dépôt et à la diffusion de documents scientifiques de niveau recherche, publiés ou non, émanant des établissements d'enseignement et de recherche français ou étrangers, des laboratoires publics ou privés. 


\section{PdPt catalyst synthesized by gas aggregation source and magnetron sputtering for fuel cell electrodes}

\section{A Caillard ${ }^{1 *}$, S Cuynet ${ }^{1}$, T Lecas ${ }^{1}$, P Andreazza $^{2}$, M Mikikian ${ }^{1}$, A-L Thomann ${ }^{1}$ and P Brault ${ }^{1}$}

${ }^{1}$ Groupe de Recherches sur l'Energétique des Milieux Ionisés (GREMI), UMR7344 Université d'Orléans - CNRS, 14 rue d'Issoudun BP6744, F-45067 Orléans Cedex 2, France

2 Interfaces, Confinement, Matériaux et Nanostructures (ICMN), UMR7374, CNRS Université d'Orléans, $1 \mathrm{~b}$ rue de la férolerie, F-45100 Orléans Cedex 2, France

* CORRESPONDING AUTHOR : amael.caillard@univ-orleans.fr, +33 (0)2 38494352 KEYWORDS. gas aggregation source, magnetron sputtering, platinum, nanoclusters, catalyst.

Abstract. PdPt catalysts with different morphologies and atomic ratios have been synthesized on native $\mathrm{SiO}_{2} / \mathrm{Si}$ and on proton exchange membrane. The combination of the gas-aggregation source and of the magnetron sputtering techniques allows the formation of quasi core-shell $\mathrm{Pd}_{0.97} \mathrm{Pt}_{0.03} @ \mathrm{Pt}$ nanoclusters. Transmission electron microscopy and grazing incidence wide angle X-ray scattering measurements on Pd-rich core reveal a mean diameter of $4 \mathrm{~nm}$ and a fcc structure. The Pt shell around the half of the Pd-rich core is formed by magnetron sputtering which leads to the increase of nanocluster diameter (up to $10 \mathrm{~nm}$ ) and of the overall Pt content (up to 85\%). The membranes coated by PdPt core catalyst and PdPt@Pt catalyst (resulting in the formation of catalyst coated membrane) are incorporated into fuel cells and their electrical characteristics are measured. The association of the two deposition techniques resulting in the formation of quasi core-shell PdPt@Pt nanoclusters improves the startup step of the fuel cell.

Submitted to Journal of Physics D: Applied Physics 


\section{Introduction}

Depending on the size range of interest and the material involved, different techniques can be used to prepare metallic nanoclusters. These include wet chemical techniques (colloidal, sol gel, water-in-oil) and physical vapor deposition (PVD) methods. Wet chemical techniques through colloidal chemistry in liquid environments, are probably the most popular. In most of these techniques, the post-removal of ligand is required which involves treatments at elevated temperatures or the application of strongly oxidizing chemicals in order to reveal active metal surface and allow sufficient strong binding of the clusters to supports. PVD techniques for the synthesis of near-monodisperse metallic nanoclusters may be the solution for avoiding post treatments which is required for some applications in heterogeneous catalysis (for example in fuel cell) involving polymers. Thermal post-treatment may induce an aggregation of the cluster and a deterioration of the sensitive polymeric substrate. Among PVD methods, plasma magnetron sputtering (MS) discharge in vacuum conditions is a convenient technique for the growth of pure metal nanoclusters. These nanoclusters result of various processes (atom diffusion and condensation) on the surface material [1]. Nanoclusters are quickly transformed into ramified islands and then into a continuous thin film when increasing the amount of sputtered materials [2], which makes difficult the synthesis of porous materials with high specific area (as random stacking of nanoclusters), nanocomposite materials (well dispersed nanoclusters embedded in a matrix) or core-shell nanoclusters. Moreover, the size and the shape of the pure metal nanoclusters is difficult to monitor for a given substrate material by using the MS technique [2].

Because of these difficulties, the gas-aggregation source (GAS) technique (based on a planar magnetron), where the nanoclusters are formed before their landing on the substrate, is attracting special interest [3, 4]. The size of the gas-phase nanoclusters can be controlled either 
by adjusting typical parameters as the power applied to the magnetron, the aggregation distance and the gas pressure, or recently by powering the magnetron cathode in pulsed sputtering regime [5-7]. Such a source is already employed for the production of a wide variety of metal nanoclusters; e.g. $\mathrm{Co}, \mathrm{C}, \mathrm{Ti}, \mathrm{Pd}, \mathrm{Pt}, \mathrm{Ag}, \mathrm{Cu}, \mathrm{Fe}$ [8-16], of a few bimetallic or metal-oxide materials; e.g. AuPd [17], NiCr [18], FePt [19], $\mathrm{CeO}_{2_{-x}}$ [20], CoAu [21], PtV, PtTi, VTi [22], $\mathrm{Ni} / \mathrm{NiO}$ [23] and may lead to various sizes and shapes (core-shell, nanorings or cubes) $[18,19$, 21-23]. Most bimetallic materials are realized by using alloy targets in the GAS or by using multiple independent targets placed at different positions in the gas aggregation area. The GAS technique is sometimes coupled to another vacuum deposition techniques (evaporation, molecular beam epitaxy and MS sputtering [4, 24-26]) in order to embed size-selected nanoparticles in matrices (nanogranular films).

Electrochemical cells, as proton exchange membrane (PEM) fuel cells with catalyst coated membrane $(\mathrm{CCM})$ architecture, require the production of well dispersed catalysts directly on a polymeric membrane [27]. In this case, the physical and chemical properties of these nanoclusters must be well controlled in order to promote their catalytic activity towards the oxygen reduction reaction [28]. Pure Pt catalyst is still the most efficient catalyst even if many attempts have been made to introduce Pt-alloy catalysts as PdPt catalyst [29]. For ultra low catalyst loading $(<25 \mu \mathrm{gPtcm}-2,7.51016$ at $\mathrm{cm}-2)$, the use of the high vacuum MS technique in order to synthesize small nanocatalysts with a 3-5 nm mean size leads to high catalyst utilization [30] (defined as the specific power delivered by the fuel cell per gram of platinum catalyst contained in the electrodes). But in such fuel cells a delay (startup) is necessary to reach the nominal power. Such delay can be related to well-known phenomena of Pt agglomeration and migration which induce an increase of the pure Pt nanoparticle size up $10 \mathrm{~nm}$ during fuel cell operation. So if the nanoparticles are synthesized in the range of 5-10 nm, the aggregation 
phenomenon can be significantly decreased and a reduced delay to reach the nominal power can be expected. A way to reduce the Pt amount is to synthesize core-shell nanocatalyst by placing the Pt atoms on the extreme surface of the nanocatalyst. Because the nanocatalyst is supported on carbon (in most cases), about half of the nanocatalyst external surface will be in contact with the reactant. The other part of the nanocatalyst is in contact with the carbon and cannot be active. This is why quasi core-shell structure with Pt only on the top of the nanocatalyst (incomplete Pt shell layer) is relevant for electrocatalyst reaction in PEMFC systems. However, the dealloying/alloying mechanism involved in the preparation of bimetallic catalyst by MS technique is difficult to control. The development of a new physical way of producing catalysts is required in order to enhance the specific area of the deposit, and to precisely control the shape, the structure and the size of the catalyst, particularly for bimetallic catalyst.

This study aims to directly deposit pre-formed PdPt nanoclusters dispersed on a proton exchange membrane using a gas aggregation source (GAS). Moreover, it will be demonstrated as being a new way of producing quasi core-shell PdPt@Pt catalytic nanoclusters for fuel cells. To achieve this aim, the GAS technique is combined with the MS discharge in a unique experiment which has been rarely performed [26]. These catalytic nanoclusters are incorporated in fuel cells and compared to Pt and PdPt catalysts, respectively made by MS and GAS techniques. The electrical characteristics of each fuel cell are measured and compared to each other, especially during the first hour of fuel cell operation.

\section{Experimental set up}

The experimental setup displayed in Fig. 1 is based on a GAS (Nanogen 50 from Mantis Deposition Ltd) coupled to a cross-shaped high vacuum (HV) deposition chamber separated by 
an outlet diaphragm (5 $\mathrm{mm}$ in diameter). The target sputtering and the synthesis of the catalytic nanoclusters occur in the aggregation source whereas the deposition on a rotating substrate holder occurs in the HV deposition chamber. A single 500 1/s turbomolecular pump connected to the deposition chamber is used to achieve a vacuum of $10^{-6}$ mbar in the deposition chamber and of $10^{-4} \mathrm{mbar}$ in the aggregation source. The distance between the outlet diaphragm and the substrate holder is set to $350 \mathrm{~mm}$. The 2 inches diameter magnetron is equipped with a $\mathrm{Pd}_{0.95} \mathrm{Pt}_{0.05}$ target, and operates in balanced mode. The distance between the target and the outlet diaphragm is fixed to $90 \mathrm{~mm}$. A one inch magnetron equipped with a Pt target is connected to a bottom flange of the deposition chamber. Its head is $30^{\circ}$ tilted which allows the $\mathrm{Pt}$ deposition on the rotating substrate by glancing MS. Two DC power supplies (Advanced Energy Pinnacle Plus) allow the ignition of the two magnetron plasmas. This experimental set up allows the synthesis of GAS based catalyst $P d P t \_G A S$, of MS based catalyst $P t \_M S$ and of GAS and MS based catalyst PdPt_GAS_MS. During GAS deposition, the 2" magnetron is current-regulated (0.1 A) and the flow of the buffer gas (Argon) is fixed to $60 \mathrm{sccm}$ resulting in a pressure of 270 $\mu$ bar and of $2.2 \mu$ bar in the aggregation source and in the deposition chamber, respectively. During MS deposition, the 1" magnetron is power-regulated (20 W) and the Ar pressure is increased to $10 \mu$ bar in the deposition chamber by using a laminar valve. Before the deposition, a quadrupole mass spectrometer (MesoQ) is inserted between the two chambers in order to measure the mass of the charged nanoclusters in the range of $2-10^{6} \mathrm{amu}$ in the growth conditions. This spectrometer is removed afterwards for deposition on the substrate. 


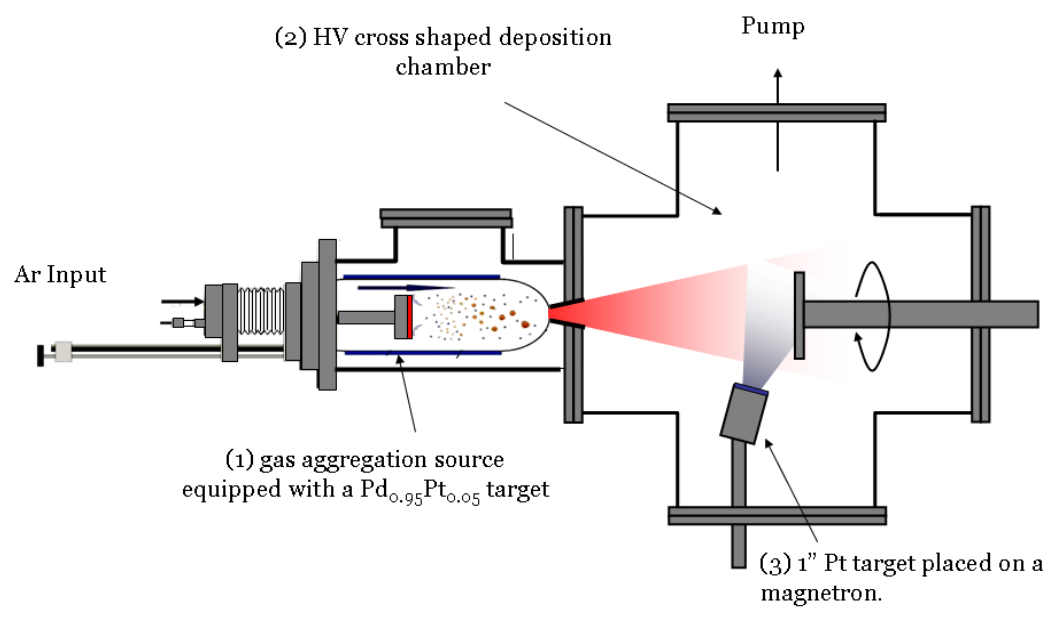

Figure 1. Schematic of the experimental set-up consisting of: (1) a GAS equipped with a $\mathrm{Pd}_{0.95} \mathrm{Pt}_{0.05}$ target, (2) a HV deposition chamber and (3) a Pt target placed on a magnetron.

In this study, two series of catalyst depositions are performed as presented in Table 1. For the three first samples, an ultra-low amount of catalytic material is deposited on $1 \mathrm{~cm}^{2}$ pieces of native $\mathrm{SiO}_{2} / \mathrm{Si}(100)$ and on a carbon-coated 200 mesh grid (Agar scientific) for transmission electron microscopy (TEM) analysis. The GAS deposition time is kept constant at one minute for the PdPt_GAS1, the PdPt_GAS1+DCMS15s and the PdPt_GAS1+DCMS1, whereas the MS deposition time is fixed to $15 \mathrm{~s}$ and $1 \mathrm{~min}$ for the PdPt_GAS1+DCMS15s and the PdPt_GAS1+DCMS1 depositions. Rutherford backscattering Spectroscopy (RBS) is used to measure the amount of $\mathrm{Pt}$ and $\mathrm{Pd}$ on the silicon substrates. For RBS measurements, the energy of the probing ${ }^{4} \mathrm{He}$ particles and the scattering angle are fixed to $2 \mathrm{MeV}$ and $165^{\circ}$, respectively. The atomic ratio $\mathrm{Pd} / \mathrm{Pt}$ on TEM grid is measured with an energy dispersive $\mathrm{X}$-ray spectrometer (EDS) detector coupled to a Transmission Electron Microscope (CM20 Philips TEM). The diameter of the nanoclusters is measured at the same time. The crystallographic structure of the PdPt_GAS1 nanoclusters (deposited on $\mathrm{SiO}_{2} / \mathrm{Si}$ ) is investigated at SIXS beamline of the Synchrotron Soleil Facility using the multi-environment diffractometer setup allowing grazing 
incidence wide angle X-ray scattering (GIWAXS) measurements [31]. The sample is irradiated by a tunable monochromatic X-ray beam just below the Pt L3 absorption edge (11461 eV). Due to the low size range of particles and low quantities of deposited metal, the X-ray grazing incidence angle $\alpha_{i}=0.15^{\circ}$ was selected close to the critical angle of total reflection of the substrate $\left(\alpha_{\mathrm{C}}=0.156^{\circ}\right.$ for $\left.\mathrm{SiO}_{2} / \mathrm{Si}\right)$ in order to reduce the scattering background from substrate and to enhance the diffraction intensity from supported clusters [32]. A standard scintillator detector positioned in the scattering direction at a fixed exit angle $\alpha_{\mathrm{f}}$ (out-of-substrate-plane angle) $=\alpha_{\mathrm{i}}$ and at a scan angle $\delta$ (in-plane angle), is used for the GIWAXS intensities measurements.

Table 1. Deposition time, weight composition and atomic ratio of the catalysts.

\begin{tabular}{|c|c|c|c|c|c|}
\hline & $\begin{array}{l}\text { GAS dep. } \\
\text { Time (min) }\end{array}$ & $\begin{array}{l}\text { MS dep. } \\
\text { Time (min) }\end{array}$ & $\operatorname{Pd}\left(\mu \mathrm{gcm}^{-2}\right)$ & $\operatorname{Pt}\left(\mu \mathrm{gcm}^{-2}\right)$ & $\begin{array}{l}\mathrm{Pd} / \mathrm{Pt} \text { atomic } \\
\text { ratio }(\%)\end{array}$ \\
\hline \multicolumn{6}{|c|}{$\begin{array}{l}\text { Ultra Low loading for morphology and structural } \\
\text { investigation }\end{array}$} \\
\hline$P d P t \_G A S 1$ & 1 & 0 & 0.4 & $<0.02$ & 97/3 (RBS) \\
\hline$P d P t \_G A S 1+M S 15 s$ & 1 & $15 \mathrm{~s}$ & 0.4 & 1.4 & $34 / 66$ (EDX) \\
\hline$P d P t \_G A S 1+M S 1$ & 1 & 1 & 0.4 & 5.4 & 12/88 (EDX) \\
\hline \multicolumn{6}{|c|}{ Low loading for fuel cell tests } \\
\hline PdPt_GAS10 & 10 & 0 & 4 & 0.2 & 97/3 (RBS) \\
\hline$P d P t \_G A S 10+M S 1$ & 10 & 1 & 2 & 5.4 & $40 / 60$ (RBS) \\
\hline$P d P t \_G A S 10+M S 2$ & 10 & 2 & 2 & 10.8 & $25 / 75$ (RBS) \\
\hline$P d P t \_G A S 10+M S 4$ & 10 & 4 & 2 & 21.6 & 15/85 (RBS) \\
\hline$P t \_M S 1$ & 0 & 1 & 0 & 5.4 & $0 / 100$ \\
\hline
\end{tabular}

For the second series (5 depositions) in Table 1, a larger amount of catalytic materials is grown on $1 \mathrm{~cm}^{2}$ pieces of native $\mathrm{SiO}_{2} / \mathrm{Si} 100$ and on $50 \mu \mathrm{m}$ thick proton exchange membrane (Nafion NRE 212) for the fuel cell tests. The GAS deposition time is increased to $10 \mathrm{~min}$ and the MS one is in the range 0-4 min. The five coated membranes are tested in real fuel cell conditions. The $9 \mathrm{~cm}^{2}$ non-prehumidified Nafion ${ }^{\circledR}$ are assembled with two microporous carbon films (called gas diffusion layer GDL, Sigracet 10BC) on both sides. The anode GDL is previously covered by $20 \mu \mathrm{g}_{\mathrm{Pt}} \mathrm{cm}^{-2}$ using the MS process, whereas the cathode GDL in contact with the 
coated side of the membrane is un-covered. The fabrication procedure of the MEA based on the PdPt_GAS10+MS4 catalytic deposition is given in Fig 2. Each asymmetric membrane electrode assembly (MEA) is then mechanically pressed at $2 \mathrm{Nm}$ torque in a $5 \mathrm{~cm}^{2}$ Paxitech cell without hot pressing. Oxygen and hydrogen gases are introduced in the PEMFC fuel cell without humidification. During the three first hours of operation, voltage pulses (period $10 \mathrm{~s}$, duty cycle $50 \%$, low level $0.35 \mathrm{~V}$, high level $0.8 \mathrm{~V}$, amplitude $0.45 \mathrm{~V}$ ) are applied on the fuel cell using a zero volt dc electronic load (AMREL ZVL100-10-80L) and the delivered current density is recorded on a PC. This procedure includes 3 steps where the temperature and the backpressure are modified: $30^{\circ} \mathrm{C} / 1.1$ bars, $30^{\circ} \mathrm{C} / 2$ bars and $50^{\circ} \mathrm{C} / 2$ bars during the first, the second and the third hour, respectively. Once the pulsed mode is finished, the polarization curves (cell voltage $E$ vs current density $j$ ) are recorded. A potentiostat (VersaSTAT 4 from Princeton Applied Research) delivers up and down voltage ramps between about $0.3 \mathrm{~V}$ and the Open Circuit Voltage (scan rate of $1 \mathrm{mVs}^{-1}$ ) and measures the current delivered by the fuel cell.

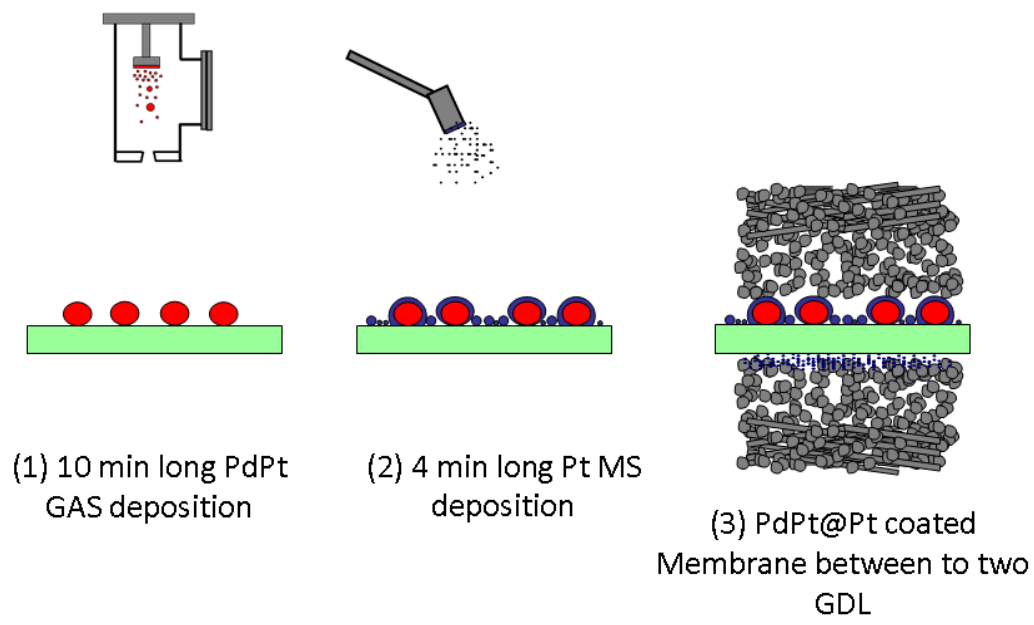

Figure 2. Fabrication procedure for the PdPt_GAS10+MS4 catalyst. 


\section{Results and discussion}

First of all, the PdPt_GAS1 deposition corresponding to the PdPt nanoclusters synthesized during one min by GAS is investigated by TEM. As shown in Fig. 3, most of the nanoclusters seem to be spherical, but a few facetted ones have been observed. A statistical analysis of three low magnification micrographs shows a nanocluster density of $610^{9} \mathrm{~cm}^{-2}$, a broad diameter range (from 2 to $7 \mathrm{~nm}$ ) with a mean diameter $<\mathrm{d}>$ of $3.9 \mathrm{~nm}$, as displayed in the size distribution inset. Fig $3 b$ gives the diameter distribution obtained from the mass spectrometer (assuming spherical particles). The distribution covers the same range of values and the mean diameter $<\mathrm{d}>$ of the negatively charged nanoclusters is $4 \mathrm{~nm}$.
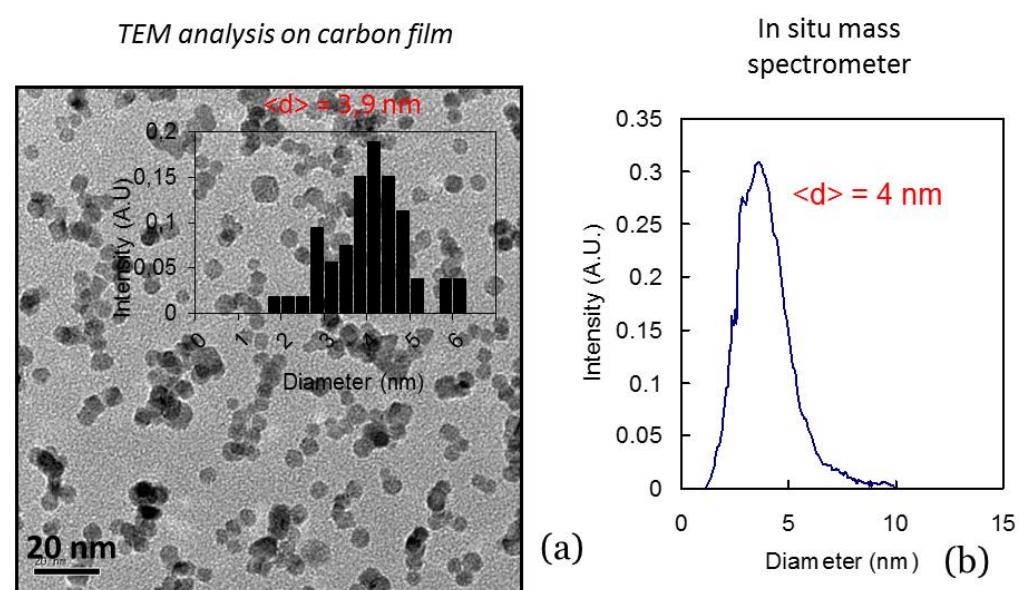

Figure 3. (a) PdPt_GAS1 deposit and size distribution obtained by TEM analysis and (b) the size distribution of PdPt_GASl obtained using in-flight mass spectrometry.

This first sample PdPt_GAS1 is then covered by platinum atoms during $15 \mathrm{~s}$ and $1 \mathrm{~min}$ using the DCMS technique. Fig. 4 displays three TEM micrographs: the PdPt_GAS1 (a), the PdPt_GAS1_DCMS15s (b) and the PdPt_GAS1_DCMS1 (c) depositions. On the inset of Fig 4a, the TEM image performed on a facetted nanocluster shows lattice fringes assigned to the face-centered cubic (fcc) Pd structure. In Fig 4b, small nanoclusters with a mean diameter of 
$2.5 \mathrm{~nm}$ appear and the diameter of the larger ones increases to $6 \mathrm{~nm}$. Such small particles are only visible when the Pt atoms are deposited by MS. The density and the diameter of these particles increase when the deposition time increases (from 15s on Fig4b to 1 min on Fig4c). Such observations indicate that the smaller particles, that clearly fill the area left after the GAS deposition, are made of Pt nanoclusters. The density of the larger ones is around 5-8 $10^{9} \mathrm{~cm}^{-2}$ which corresponds to the nanocluster density of the PdPt_GAS1 sample. These large nanoclusters correspond to the $3.9 \mathrm{~nm} P d P t$ nanoclusters covered by Pt atoms. On Fig 4c, the amount of material on the carbon film is too large to determine a precise nanocluster size distribution. Nevertheless, nanoclusters with a diameter larger than $10 \mathrm{~nm}$ are present on the surface, which corresponds to GAS prepared nanoclusters covered by a shell of Pt atoms. As shown in the inset, a shell appears on the half of the PdPt core nanocluster and its thickness is not homogeneous all around the PdPt nanoclusters. This last TEM micrograph indicates that quasi core-shell PdPt@Pt nanoclusters are formed by combining GAS and MS techniques.

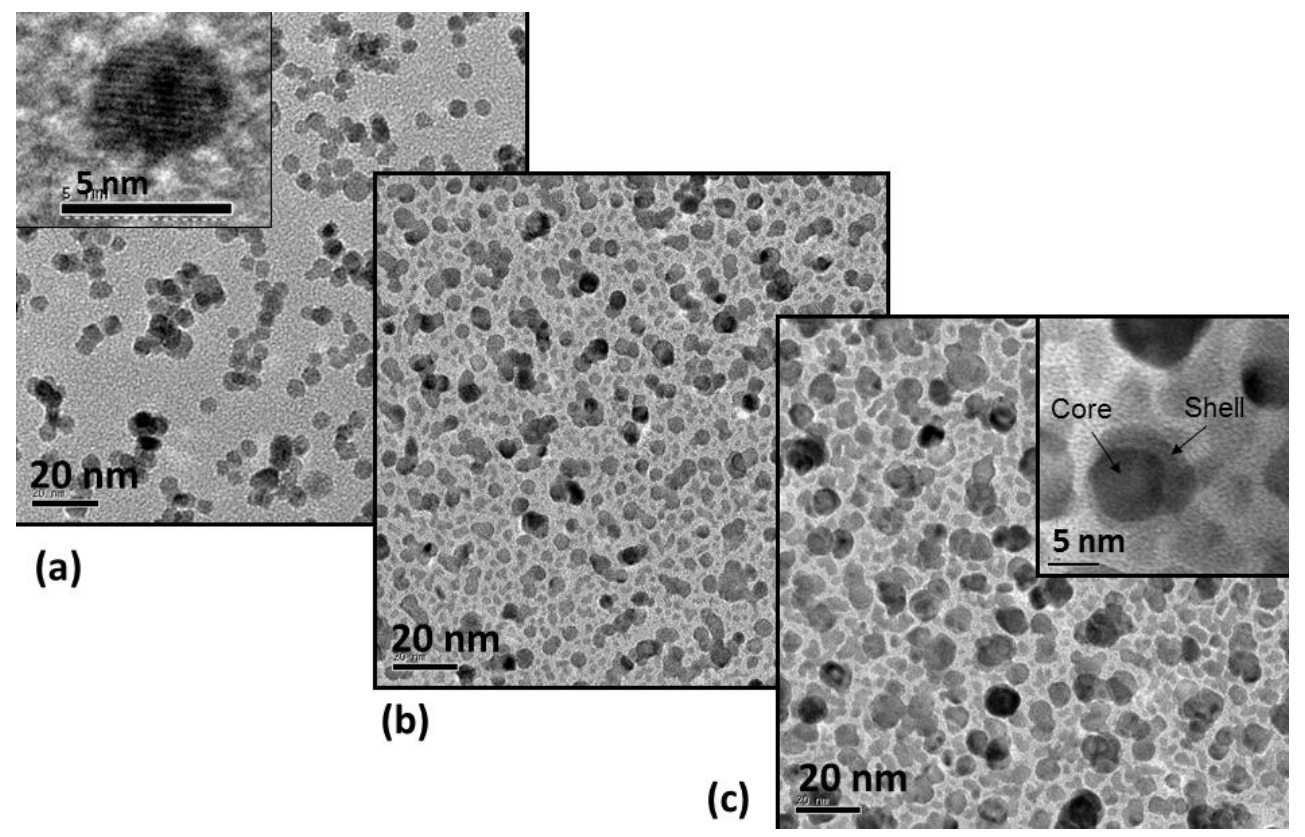

Figure 4. TEM micrographs of the PdPt_GAS1 (a), the PdPt_GAS1_DCMS15s (b) and the PdPt_GAS1_DCMS1 (c) depositions. The two insets correspond to high resolution TEM micrographs for the PdPt_GAS1 and of the PdPt_GAS1_DCMS1 depositions. 
A preliminary analysis of the diffraction pattern (Fig 5) confirms the fcc structure of the PdPt_GAS1 sample with the (111), (200), (220), (311) and (222) characteristic peaks. The peak positions correspond to an average nearest neighbor distance of $0.277 \mathrm{~nm}$, higher that the evaluated value of $0.275 \mathrm{~nm}$ from the bulk Vegard law. This behavior is not in agreement with Lamber et al. work which reports that small Pd particles with mean diameters ranging from 1.4 to $5 \mathrm{~nm}$ show a decrease of the Pd lattice parameter with decreasing size of palladium cluster [33]. In our case, small content of Pt atoms seems to induce a small expansion of the lattice constant close to the Pt value which could favor the formation of a pseudomorphic interface (lattice matching) when Pt post deposition occurs.

In addition, the scattering profiles are not in agreement with a polycrystalline material with perfect crystalline grains (Fig. 5). A structural analysis method based on the Debye equation $[31,34]$ is performed coupled with cluster model calculations taking into account structural disorder, strain or plane defects. The experimental diffraction pattern (PdPt_GAS1) compared with different calculated cluster structures (around $5 \mathrm{~nm}$ in size) in facetted (111) and (100) truncated octahedral (TOh) shape shows that the clusters contains (111) twins and stacking faults (planar defects), which induce small strain mainly in planes disoriented with respect to (111) plane, as (002) [35,36]. This results confirm the presence of facetted nanoparticles observed in a few TEM micrographs (Fig 4a). 


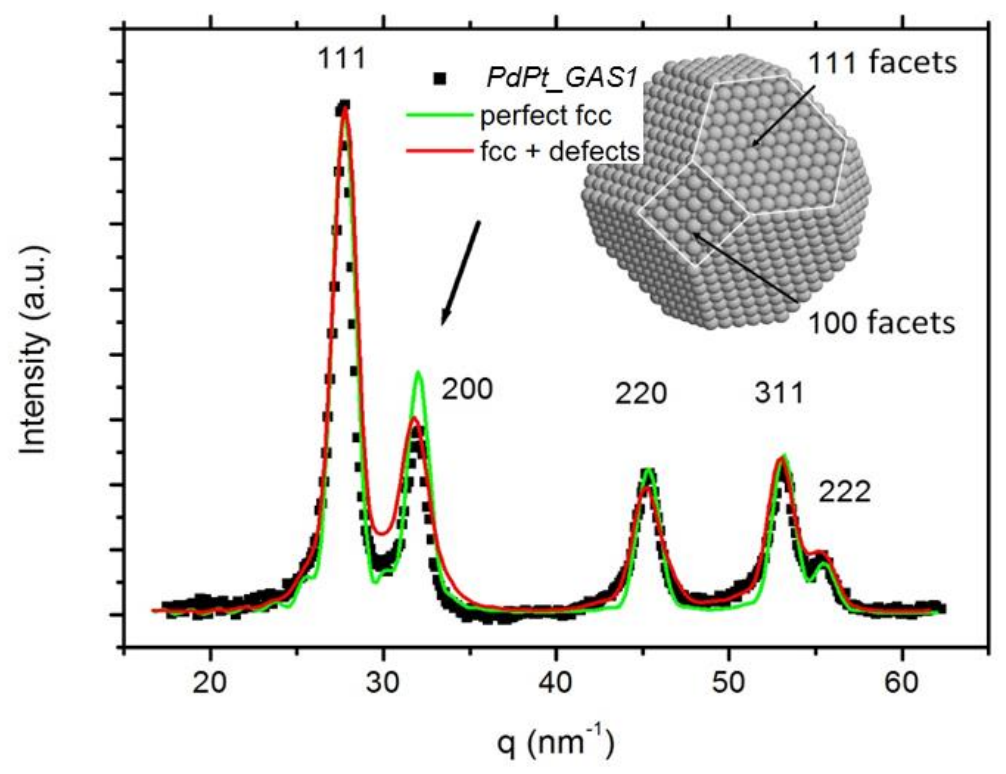

Figure 5. Wide angle $\mathrm{x}$ - ray scattering pattern of the PdPt_GAS1 sample compared with a calculated pattern of perfect fcc clusters (TOh shape) and clusters with (111) stacking faults and twins adjusted with the interatomic distance of $0.277 \mathrm{~nm}$.

Five direct depositions on proton exchange membrane using conditions PdPt_GASI0, PdPt_GAS10_MS1,PdPt_GAS10_MS2,PdPt_GAS10_MS4 and Pt_MS1 are tested as s in five asymmetric membrane electrode assemblies (MEA). Fig. 6a displays the $5 \mathrm{~cm}^{2} P d P t \_G A S 10$ deposition on a $16 \mathrm{~cm}^{2}$ square membrane. We previously measured the diameter of the nanocluster beam by the insertion of a white paper sheet at the substrate holder position in the deposition chamber. The black spot on Fig.6b is nearly circular and its diameter is close to 10 $\mathrm{cm}$. From this observation, we assume that the deposition is nearly homogenous on the $5 \mathrm{~cm}^{2}$ membrane. 

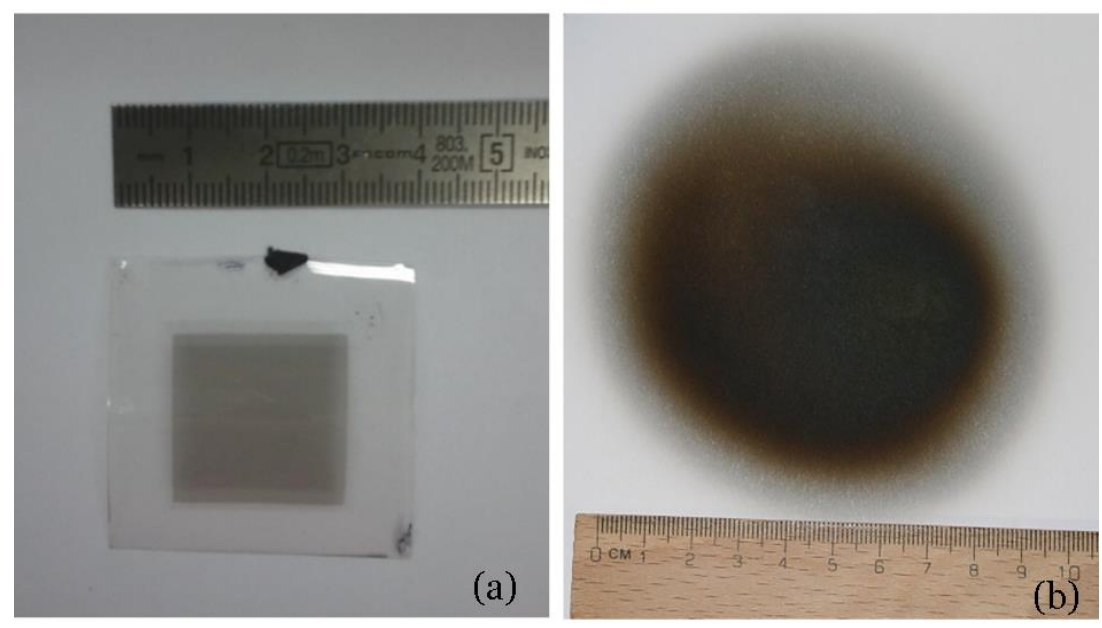

Figure 6. Pictures of a proton exchange membrane (a) and of a white paper sheet (b) covered by nanoclusters (PdPt_GAS10)

Fig.7a. displays the first hour of pulsed startup. At the beginning, all the MEA containing a cathode prepared by GAS deliver a current of 0.4-0.6 A, whereas the only one without such a cathode, $P t \_M S 1$ (red, E), shows a current of about 0.1 A. After one hour, the currents delivered by all MEA, except the PdPt_GAS10 based one (black, A), increase by 0.4-0.55 A. Even if the current delivered by the PdPt_GAS10 based MEA starts at high values, the current only increases by $0.2 \mathrm{~A}$ during the first hour. It can be deduced from these measurements that the association of MS and GAS technique resulting in the formation of quasi-core-shell PdPt@Pt nanoclusters improves the startup of the fuel cell during the first hour. Such observation probably means that the mechanisms affecting the nanocluster size are different for the PdPt@Pt and the Pt nanocatalyst. As mentioned before, the size of the pure Pt nanoparticles (corresponding to Pt_MS1) increases during the fuel cell running in order to reach the range of 5-10 nm. The diameter of the fresh quasi core-shell PdPt@Pt nanocatalyst is already in this range of values which may reduce the migration and aggregation phenomena. 

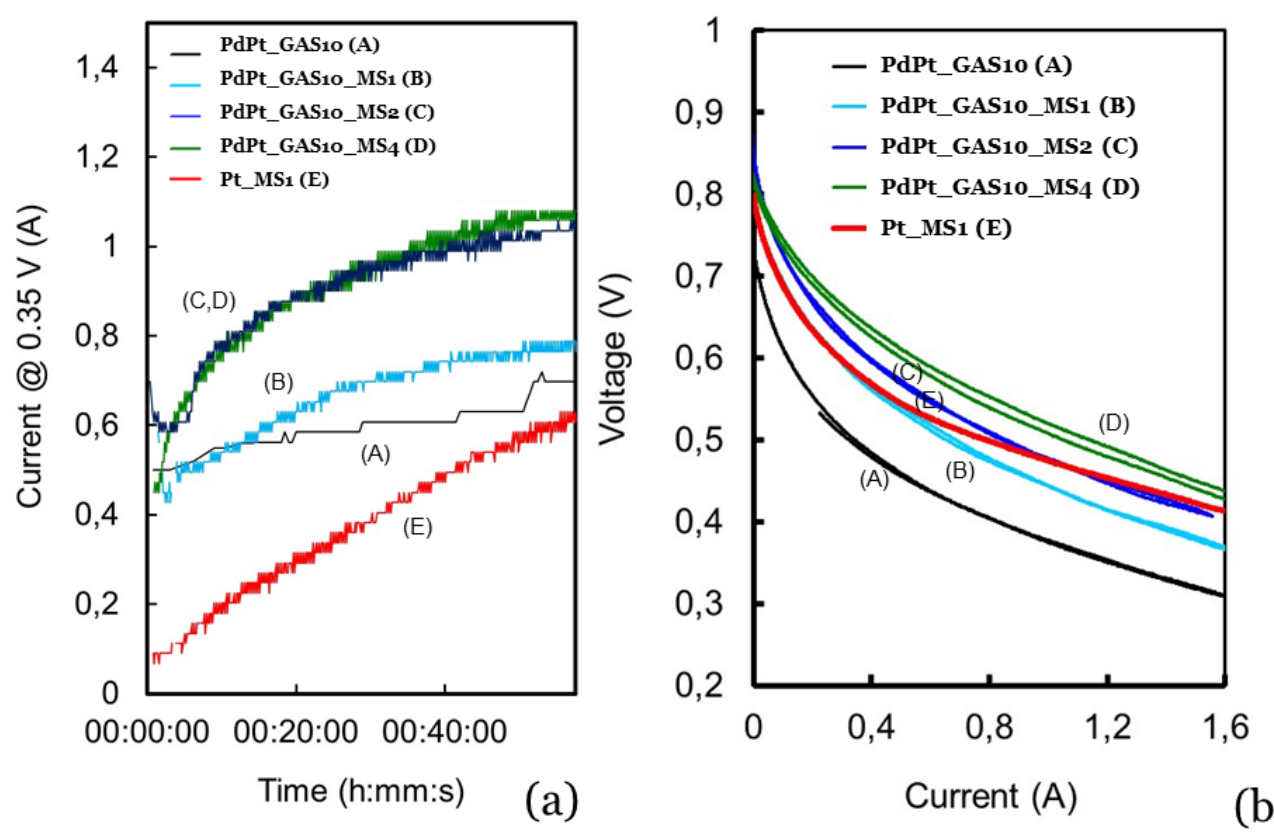

Figure 7. (a) Current delivered by five MEA during the first operating hour. Experimental conditions: period $10 \mathrm{~s}$, duty cycle $50 \%$, low level $0.35 \mathrm{~V}$ and high level $0.8 \mathrm{~V}$. and (b) Cell voltage $E$ vs current density $j$ for the five tested MEA. Experimental conditions: 2 bars; $50{ }^{\circ} \mathrm{C}$. Nafion NRE212, three identical anodes prepared by the deposition of $20 \mu \mathrm{g}_{\mathrm{Pt}} \mathrm{cm}^{-2}$ by MS on GDL Sigracet 10BC.

After two more hours in pulsed conditions (pulse amplitude of $450 \mathrm{mV}$ in $10 \mathrm{~s}$ ), the polarization curves for each MEA are registered at a low scan rate of $1 \mathrm{mVs}^{-1}$. The MEA containing the PdPt_GAS10 (black, A) cathode gives the lowest voltage over the all current range. The curves are shifted to higher voltage for increasing amount of platinum prepared by MS. The two MEA containing the same amount of platinum on the cathode side, PdPt_GAS10_MS1 (light blue, B) and Pt_MS1 (red, E), leads to the same voltage at low current but the addition of PdPt nanoclusters by the GAS technique leads to an increase of the MEA resistivity at high current. Thus, the voltage decrease (over $0.4 \mathrm{~A}$ ) for the PdPt_GAS10_MS1 based MEA is much more pronounced than the one for the Pt_MSI based MEA. We evidenced that the addition of PdPt 
nanoclusters prepared by the GAS technique before the Pt deposition by MS improves the startup of the fuel cell but does not lead to a significant increase of the fuel cell performance.

\section{Conclusion}

For the first time, bimetallic PdPt nanoclusters have been synthesized by the GAS technique and have been incorporated in an operating fuel cell. In this study, the GAS technique has been associated with the MS technique in order to synthesize bimetallic PdPt nanoclusters with different morphologies and atomic compositions. The use of the GAS technique allows the formation of alloyed $\mathrm{Pd}_{0.97} \mathrm{Pt}_{0.03}$ nanoclusters with a mean diameter of $4 \mathrm{~nm}$, whereas quasi core-shell $\mathrm{Pd}_{0.97} \mathrm{Pt}_{0.03} @ \mathrm{Pt}$ nanoclusters are formed by the successive use of GAS and MS techniques on native $\mathrm{SiO}_{2} / \mathrm{Si}(100)$ and on proton exchange membrane. Grazing incidence wide angle X-ray scattering GIWAXS measurements on alloyed PdPt nanoclusters (performed at SIXS beamline at the Synchrotron Soleil Facility) indicates specific strained structures with low content of Pt atoms which favor (100) and (111) facets. The PdPt cluster lattice parameter matches with the pure Pt lattice which was post-deposited. Five PEM such coated by PdPt nanoclusters have been incorporated in fuel cells and the delivered current has been measured versus the startup time and versus the cell voltage. The startup of the fuel cell was improved by the addition of PdPt@Pt nanoclusters but this does not lead to an improvement of the cell performance at the steady state. This study makes the proof of the concept for a "one step" production of bimetallic nanoclusters at low temperature. This might be well suited for several applications requiring porous and nanocomposite materials, well defined and/or core-shell nanoclusters involved in electrochemistry, photovoltaic, cosmetic and biomedical applications.

\section{Acknowledgements}

This work has been supported by the CNRS (Dust4Pem project). A. SAULDUBOIS, C. ANDREAZZA, T. SAUVAGE and B. COURTOIS are acknowledged for TEM and RBS analysis from the Centre de Microscopie Electronique - CEM of University of Orléans and the 
CEMHTI Van de Graff set up, respectively. The authors thank the SOLEIL French synchrotron committee for beam time allocation and the SIXS beamline staff for technical assistance during X-ray scattering experiments. We are grateful to C. COUTANCEAU for fruitful discussions. 


\section{References}

[1] Thomann A-L, Rozenbaum J P, Brault P, Andreazza-Vignolle C, Andreazza P 2000 Appl. Surf. Science 158 172-183

[2] Kratochvíl J, Kuzminova A, Kylián O, Biederman H 2015 Surface \& Coatings Technology, in press

[3] Wegner K, Piseri P, Vahedi Tafreshi H, Milani P 2006 J. Phys. D: Appl. Phys. 39 R439R459

[4] Binns C, Trohidou K N, Bansmann J, Baker S H, Blackman J A, Bucher J-P, Kechrakos D, Kleibert A, Louch S, Meiwes-Broer K-H, Pastor G M, Perez A and Xie Y 2005 J. Phys. D: Appl. Phys. 38 R357-R379

[5] V. Stranak, S. Block, S. Drache, Z. Hubicka, C. A. Helm, L. Jastrabik, M. Tichy and R. Hippler, Surf. Coat. Technol., 2011, 205, 2755-2762.

[6] C. H. Zhang, H. Tsunoyama, H. Akatsuka, H. Sekiya, T. Nagase and A. Nakajima, J. Phys. Chem. A, 2013, 117, 10211-10217.

[7] S. Drache, V. Stranak, F. Berg, Z. Hubicka, M. Tichy, C. A. Helm and R. Hippler, Phys. Status Solidi A, 2014, 211, 1189-1193.

[8] Kylián O, Valeš V, Polonskyi O, Pešička J, Čechvala J, Solař P, Choukourov A, Slavínská D, Biederman H 2012 Materials Letters 79 229-231

[9] Watanabe Y, Wu X, Hirata H and Isomura N 2011 Catal. Sci. Technol. 1 1490-1495

[10] Quesnel E, Pauliac-Vaujour E, Muffato V 2010 Journal of Appl. Phys. 107054309

[11] Ayesh A I, Thaker S, Qamhieh N, Ghamlouche H 2011 J Nanopart Res 13 1125-1131

[12] Drabik M, Choukourov A, Artemenko A, Polonskyi O, Kylian O, Kousal J, Nichtova L, Cimrova V, SlavinskaD and Biederman H 2011 J. Phys. Chem. C 115 20937-20944

[13] Gojdka B, Hrkac V, Strunskus T, Zaporojtchenko V, Kienle L, Faupel F 2011 Nanotechnology 22465704 
[14] Bouchat V, Feron O, Gallez B, Masereel B, Michiels C, Vander Borght T, Lucas S 2011 Surface \& Coatings Technology 205 S577-S581

[15] Ten Brink G H, Krishnan G, Kooi B J, Palasantzas G 2014 Journal of Applied Physics 116 104302

[16] Koch S A, Palasantzas G, Vystavel T, De Hosson J Th M, Binns C, Louch S 2005 Phys. Rev. B 71085410

[17] Pérez-Tijerina E, Gracia Pinilla M, Mejia-Rosales S, Ortiz-Méndez U, Torres A, JoséYacaman M 2008 Faraday Discuss. 138 353-362

[18] Serdio V M, Gracia-Pinilla M A, Velumani S, Perez-Tijerina E G, van der Wiel W G 2010 Journal of Nano Research 9 101-108

[19] Wang R, Dmitrieva O, Farle M, Dumpich G, Acet M, Mejia-Rosales S, Perez-Tijerina E, Jose Yacaman M, Kisielowski C 2009 The Journal of Physical Chemistry C 4395-4400

[20] Spadaro M C, D’Addato S, Gasperi G, Benedetti F, Luches P, Grillo V, Bertoni G, and Valeri S 2015 Beilstein J. Nanotechnol. 6 60-67

[21] Mayoral A, Llamosa D, Huttel Y 2015 Chem. Commun. 518442

[22] Johnson G E, Colby R, Laskin J 2015 Nanoscale 73491

[23] D’Addato S, Spadar M C, Luches P, Grillo V, Frabboni S, Valeri S, Ferretti A M, Capetti E, Ponti A 2014 Applied Surface Science 306 2-6

[24] Binns C, Maher M J, Pankhurst Q A, Kechrakos D, Trohidou K N 2002 Phys. Rev. B 66 184413

[25] Balasubramanian B, Kraemer K L, Reding N A, Skomski R, Ducharme S, Sellmyer D J 2010 Nano 4 1893-1900

[26] Gojdka B, Zaporojtchenko V, Hrkac V, Xiong J, Kienle L, Strunskus T, Faupel F 2012 Appl. Phys. Lett. 100133104

[27] O’Hayre R, Lee S J, Cha S W, Prinz F B 2002 J. of Power Sources 109 483-493 
[28] Coutanceau C, Urchaga P, Brimaud S, Baranton S 2012 Electrocatalysis 3 75-87

[29] Mougenot M, Caillard A, Brault P, Baranton S, Coutanceau C 2011 International Journal of Hydrogen Energy 36 8429-8434

[30] Brault P, Caillard A, Baranton S, Mougenot M, Cuynet S, Coutanceau C 2013 ChemSusChem 6 1168-1171

[31] Wilson A, Bernard R, Vlad A, Borensztein Y, Coati A, Croset B, Garreau Y, Prévot G 2014 Phys. Rev. B 90075416

[32] Penuelas J, Andreazza P, Andreazza-Vignolle C, Tolentino H C N, De Santis M, Mottet C 2008 Phys. Rev. Lett. 100115502

[33] Lamber R, Wetjen S, Jaeger N I 1995 Phys. Rev. B 5110968

[34] Andreazza P in « Nanoalloys: Synthesis, Structure and Properties » 2012 Eds D.Alloyeau et al., 69-114 Springer-Verlag, London.

[35] Longo A, Martorana A 2008 J. Appl. Cryst. 41 446-455

[36] Penuelas J, Andreazza P, Andreazza-Vignolle C, Mottet C, De Santis M, Tolentino H C N 2009 Eur. Phys. J. 16719 